This Association has suffered the loss by death of one of its oldest members in the person of J. D. St. Clair Maclardy, M.A., a distinguished graduate of the University of Sydney, a well-known and faithful servant of the Education Department of this State: and who was successively lecturer in the Teachers' College, for a short period its Principal, and finally Chief Examiner.

\title{
ERRATA.
}

Vol. XIV, p. 16, 1. 6, for $a^{\prime}$ read $a^{\prime}|A|$. p. 23, 1. 14 up, for Guyaelf read myself.

\section{THE PROBLEM.}

(By courtesy of the Editor of the Observer.)

IF right and wrong were only plus

And minus, 'twould be well for us ;

If reckoning up the life's amount

Were but a matter of account ;

If we were able to assess

Virtue in Mammon's balances,

And weigh out like a pound of tea

Courage and faith and charity ;

If two and two were always four,

And never less, and never more,

In that strange sum the Master sets-

Then one could toil, without regrets,

To puzzle the solution out,

And value $x$ beyond a doubt.

But no kind axioms control

The mathematics of the soul ;

Where definitions grow and fade,

And postulates are patched and frayed,

And ratios get out of hand,

Like Alice's in Wonderland ;

And curious relativities

Upset our decimals and $\pi$ 's ;

And $a$ 's are b's, and odds are evens

(The very sixes may be sevens!)

And good and bad, and wrong and right

Are hard to recognise at sight-

How, in this quandary, can we

Expect to reach the Q.E.D. ?

F. H.

Observer, 1927, Dec. 11.

\section{ROBERT WILLIAM GENESE}

MAY 8, 1848-JANUARY 22, 1928 